Article

\title{
Effect of Nitrogen/Oxygen Substances on the Pyrolysis of Alkane-Rich Gases to Acetylene by Thermal Plasma
}

\author{
Wei Huang, Junkui Jin, Guangdong Wen, Qiwei Yang * (D), Baogen Su * and Qilong Ren \\ Key Laboratory of Biomass Chemical Engineering, College of Chemical and Biological Engineering, \\ Zhejiang University, Hangzhou 310027, China; 18771100342@163.com (W.H.); jinjunkui@126.com (J.J.); \\ zdwgd@zju.edu.cn (G.W.); renql@zju.edu.cn (Q.R.) \\ * Correspondence: yangqw@zju.edu.cn (Q.Y.); subg@zju.edu.cn (B.S.); Tel.: +86-571-87951125 (Q.Y.)
}

Received: 23 December 2017; Accepted: 29 January 2018; Published: 2 February 2018

\begin{abstract}
It is important to convert alkane-rich gases, such as coke oven gas, to value-added chemicals rather than direct emission or combustion. Abundant nitrogen/oxygen substances are present in the actual alkane-rich gases. However, the research about how they influence the conversion in the pyrolysis process is missing. In this work, a systematic investigation on the effect of various nitrogen/oxygen-containing substances, including $\mathrm{N}_{2}, \mathrm{CO}$, and $\mathrm{CO}_{2}$, on the pyrolysis of $\mathrm{CH}_{4}$ to $\mathrm{C}_{2} \mathrm{H}_{2}$ was performed by a self-made $50 \mathrm{~kW}$ rotating arc thermal plasma reactor, and the pyrolysis of a simulated coke oven gas as a model of alkane-rich mixing gas was conducted as well. It was found that the presence of $\mathrm{N}_{2}$ and $\mathrm{CO}_{2}$ was not conducive to the main reaction of alkane pyrolysis for $\mathrm{C}_{2} \mathrm{H}_{2}$, while $\mathrm{CO}$, as a stable equilibrium product, had little effect on the cracking reaction. Consequently, it is suggested that a pretreatment process of removing $\mathrm{N}_{2}$ and $\mathrm{CO}_{2}$ should be present before pyrolysis. Both input power and feed rate had considerable effect on the pyrolysis of the simulated coke oven gas, and a $\mathrm{C}_{2} \mathrm{H}_{2}$ selectivity of $91.2 \%$ and a yield of $68.3 \%$ could be obtained at an input power of $17.9 \mathrm{~kW}$.
\end{abstract}

Keywords: thermal plasma; pyrolysis; alkane-rich gas; acetylene; coke oven gas

\section{Introduction}

As the essential material basis for human survival and development, petroleum, coal, natural gas, and other fossil fuels support the development of human civilization and economy. The utilization process of fossil fuels produce a great deal of alkane-rich gases as their main product or byproduct, such as coke oven gas, refinery gas, natural gas and unconventional natural gas (coalbed methane, shale gas, and tight sandstone gas). For example, the coke-making process produces coke oven gas (COG) as a byproduct, and typically 1.25-1.65 tons of coal produce a single ton of coke, along with approximately $300-360 \mathrm{~m}^{3}$ of COG (6-8 GJ/t coke) [1]. Although there are reports that using those alkane-rich gases as feedstocks of chemicals, most of them are still utilized as fuel by combustion (ca. 70-80\%) or directly discharged into the atmosphere without treatment or as a torch, not only causing significant waste of resources, but also producing large amounts of greenhouse gases and hazardous pollutants which jeopardize the environment. Therefore, it is of great importance to develop more ways to convert alkane-rich gases to value-added chemicals through effective reactions.

Acetylene, known as the "mother of organic chemical products", plays a very important role not only in the field of metal processing, welding and cutting [2], but also in the production of poly(vinyl chloride) (PVC), trichloroethylene, vinyl acetate, acrylonitrile, poly-acrylonitrile [3], etc. Its abundant downstream products attract the growing pursuit in the chemical industry for alternative production methods of acetylene, because the two conventional methods-calcium carbide hydrolysis and 
partial oxidation of methane-have shown obvious shortcomings in energy cost, water consumption, and pollution [4]. In this context, increasing attention has been paid to studies on thermal plasma pyrolysis of hydrocarbons to acetylene. Acetylene is the main long-lived metastable intermediate product of pyrolysis in a hydrogen atmosphere at high temperatures $(\mathrm{T}>1800 \mathrm{~K})$; therefore, it can be obtained as the main hydrocarbon product as long as the product gas is rapidly cooled after pyrolysis to prevent further conversion to carbon black and hydrogen [5]. Due to the ultrahigh reactivity of thermal plasma, this method can effectively convert various hydrocarbons to acetylene-rich gaseous products within milliseconds, along with very little water consumption and $\mathrm{CO}_{2}$ discharge. In addition to solid and liquid hydrocarbon-rich feedstocks, such as coal, polyethylene, and aromatic compounds [6-10], gaseous alkanes can also be converted to acetylene-rich products with high acetylene yield and selectivity by this method [11,12], which creates a new method for the utilization of alkane-rich gas. However, one significant problem in the current studies on plasma pyrolysis of alkanes or alkane-rich gases is that little attention has been paid to the effect of nitrogen/oxygen-containing substances on the pyrolysis. Actually, there are always various nitrogen/oxygen-containing substances, such as $\mathrm{N}_{2}$, $\mathrm{CO}, \mathrm{CO}_{2}$, and $\mathrm{O}_{2}$, in practical alkane-rich gasses, and their concentrations are highly inconstant within a range of approximately $0.1-15 \%$. In addition to the alkanes, these compounds may also be strongly activated by the thermal plasma, leading to different gaseous products from the ideal pure-alkane case, thus, it is imperative to explore how the variety and concentration of nitrogen/oxygen-containing substances would influence the gas conversion and the product composition. It is not only essential to evaluate the intrinsic performance of the pyrolysis process, but also indispensable to establish an optimum separation-pyrolysis-separation integral process. That is, whether a pre-separation of any nitrogen/oxygen-containing compound from alkanes is needed before pyrolysis, and what kinds of purification procedures are needed after pyrolysis, strongly depend on the effect of those compounds on pyrolysis.

In this work, we systematically investigated the effect of various nitrogen/oxygen-containing substances, including $\mathrm{N}_{2}, \mathrm{CO}$, and $\mathrm{CO}_{2}$ on the pyrolysis of methane to acetylene by thermal plasma, and conducted the pyrolysis of simulated coke oven gas as a model of alkane-rich mixing gas. A self-made rotating arc plasma reactor was employed to pyrolyze those alkane-rich gases for the first time, because it was proved to have notable advantages in feedstock-plasma mixing and temperature homogenization over conventional thermal plasma reactors. The experimental results indicated that $\mathrm{CO}_{2}$ and $\mathrm{N}_{2}$ had palpable and negative effects on the pyrolysis process, thus, it is advisable to remove them from the mixing gas before pyrolysis. $\mathrm{CO}$ has little effect on the pyrolysis, thus, it can be removed after pyrolysis for an easier separation. Additionally, the operating conditions, including input power and feed rate, significantly affected not only the yield and selectivity of the products, but also the conversion efficiency of alkanes and the specific energy requirement of acetylene.

\section{Materials and Methods}

\subsection{Materials}

$\mathrm{CH}_{4}, \mathrm{C}_{2} \mathrm{H}_{6}, \mathrm{H}_{2}, \mathrm{CO}, \mathrm{CO}_{2}, \mathrm{~N}_{2}$, and Ar (all gases had a purity of $99.99 \%$ ) were purchased from Hangzhou Jingong Special Gas Co, Ltd. (Hangzhou, China). Sodium hydroxide was obtained from Sinopharm Chemical Reagent Co, Ltd. (Shanghai, China). Sodium chloride, potassium chromate, silver nitrate, and rose red reagent were purchased from Aladdin Reagent Co. Ltd. (Shanghai, China). The composition of the simulated coke oven gas is presented in Table 1, which was produced according to the main components of actual coke oven gas [13].

\subsection{Reactor Setup}

A $50 \mathrm{~kW}$ rotating arc plasma reaction device system was used in this experiment, as shown in Figure 1a, mainly consisting of four parts: a constant current power supply, plasma reactor, cooling and quenching system, and a data acquisition and control system. Figure $1 \mathrm{~b}$ shows the structure of the 
$50 \mathrm{~kW}$ rotating arc plasma reactor, mainly including a cathode, cathode flange, anode, anode upper flange, anode bottom flange, and the excitation coil. The excitation coil is sheathed outside the anode sleeve generating a magnetic field under the action of impressed current, to produce the Lorenz force in the reactor, which results in a high-speed rotation of the arc.

Table 1. The basic composition of practical coke oven gas (a) and simulated coke oven gas (b) in this work.

\begin{tabular}{|c|c|c|c|c|c|c|c|c|}
\hline \multirow{4}{*}{ (a) } & $\begin{array}{c}\text { Main } \\
\text { Component }\end{array}$ & $\mathrm{H}_{2}$ & $\mathrm{CH}_{4}$ & $\mathrm{C}_{\mathrm{m}} \mathrm{H}_{\mathrm{n}}$ & $\mathrm{CO}$ & $\mathrm{CO}_{2}$ & $\mathrm{O}_{2}$ & $\mathrm{~N}_{2}$ \\
\hline & Vol \% & $55-60$ & $23-27$ & $2-4$ & $5-8$ & $1.5-3$ & $0.3-0.8$ & $3-7$ \\
\hline & Impurity & $\mathrm{NH}_{3}$ & benzene & $\mathrm{HCN}$ & $\mathrm{H}_{2} \mathrm{~S}$ & organic sulfur & naphthalene & Tar \\
\hline & $\mathrm{g} / \mathrm{Nm}^{3}$ & $\leq 0.05$ & $\leq 2$ & $\leq 0.3$ & $\leq 0.02$ & $\leq 0.05$ & $\leq 0.1$ & $\leq 0.05$ \\
\hline \multirow[t]{2}{*}{ (b) } & $\begin{array}{c}\text { Main } \\
\text { Component }\end{array}$ & $\mathrm{H}_{2}$ & $\mathrm{CH}_{4}$ & $\mathrm{C}_{2} \mathrm{H}_{6}$ & $\mathrm{CO}$ & $\mathrm{CO}_{2}$ & $\mathrm{~N}_{2}$ & $\mathrm{Ar}$ \\
\hline & Vol \% & 56.00 & 27.00 & 3.01 & 6.09 & 2.02 & 4.88 & 1.00 \\
\hline
\end{tabular}

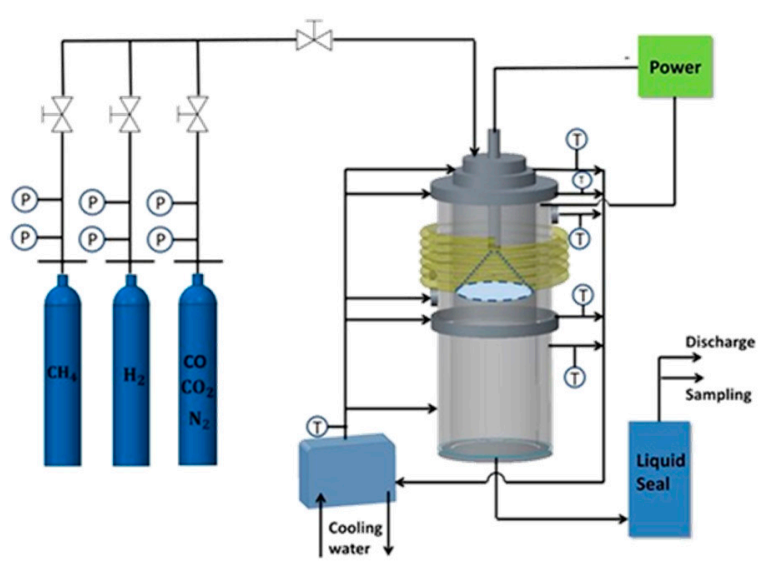

(a)

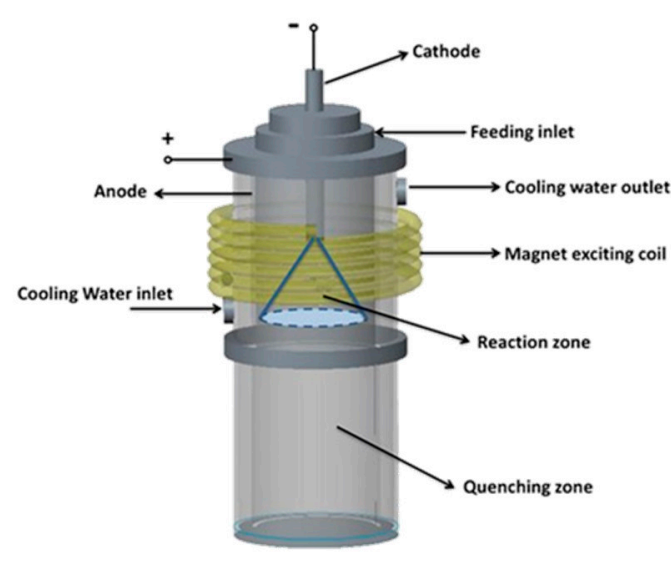

(b)

Figure 1. The $50 \mathrm{~kW}$ rotating arc plasma reactor. (a) Reaction device; and (b) the reactor structure.

\subsection{Gas Analysis}

The components of pyrolysis gas are complex, possibly including $\mathrm{CH}_{4}, \mathrm{C}_{2} \mathrm{H}_{2}, \mathrm{C}_{2} \mathrm{H}_{4}, \mathrm{C}_{2} \mathrm{H}_{6}, \mathrm{CO}$, $\mathrm{CO}_{2}$, and $\mathrm{N}_{2}$, and it is convenient to adopt gas chromatography for analysis with GC 1690 provided by Hangzhou Kexiao Chemical Equipment Co, Ltd. (Hangzhou, China). The chromatographic columns are a PLOT 5A zeolite-packed column provided by Hangzhou Kexiao Chemical Equipment Co, Ltd. (Hangzhou, China) and a PLOT Q capillary column from Agilent Technologies Co, Ltd. (Hangzhou, China). As a possible product in the nitrogen reaction, $\mathrm{HCN}$ is highly toxic and must be carefully handled. The relatively safe and simple $\mathrm{AgNO}_{3}$ titrimetric method was adopted, using a $\mathrm{NaCl}$ standard solution $(0.0100 \mathrm{~mol} / \mathrm{L})$ to calibrate the standard solution of $\mathrm{AgNO}_{3}(0.0100 \mathrm{~mol} / \mathrm{L})$, then determining the concentration of cyanide ions in the collection solution with a calibrated $\mathrm{AgNO}_{3}$ solution. The cyanide ion collecting solution is obtained by slowly accessing the sample bag gas (about $2 \mathrm{~L}$ ) to $0.1 \mathrm{~mol} / \mathrm{L} \mathrm{NaOH}$ solution to be absorbed.

\subsection{Data Processing Method}

Carbon yield $(Y)$ of acetylene in the product is generally defined as:

$$
Y_{\mathrm{C}_{2} \mathrm{H}_{2}}=\frac{2 \times Q_{\mathrm{C}_{2} \mathrm{H}_{2}}}{Q_{\mathrm{CH}_{4}}^{0}} \times 100 \%
$$


Carbon conversion efficiency $(C E)$ of the feed gas is generally defined as:

$$
C E_{\mathrm{CH}_{4}}=\left(1-\frac{Q_{\mathrm{CH}_{4}}}{Q_{\mathrm{CH}_{4}}^{0}}\right) \times 100 \%
$$

Selectivity $(S)$ of acetylene is defined as:

$$
S_{\mathrm{C}_{2} \mathrm{H}_{2}}=\frac{Y_{\mathrm{C}_{2} \mathrm{H}_{2}}}{\mathrm{CE}_{\mathrm{CH}_{4}}} \times 100 \%
$$

When pyrolyzed, the siimulated coke oven gas is defined as:

$$
\begin{gathered}
Y_{\mathrm{C}_{2} \mathrm{H}_{2}}=\frac{2 \times Q_{\mathrm{C}_{2} \mathrm{H}_{2}}}{Q_{\mathrm{CH}_{4}}^{0}+2 \times Q_{\mathrm{C}_{2} \mathrm{H}_{6}}^{0}} \times 100 \% \\
C E_{\mathrm{CH}_{4}+\mathrm{C}_{2} \mathrm{H}_{6}}=\left(1-\frac{Q_{\mathrm{CH}_{4}}+2 \times Q_{\mathrm{C}_{2} \mathrm{H}_{6}}}{Q_{\mathrm{CH}_{4}}^{0}+2 \times Q_{\mathrm{C}_{2} \mathrm{H}_{6}}^{0}} \times 100 \%\right. \\
S_{\mathrm{C}_{2} \mathrm{H}_{2}}=\frac{Y_{\mathrm{C}_{2} \mathrm{H}_{2}}}{\mathrm{C}_{\mathrm{CH}_{4}+\mathrm{C}_{2} \mathrm{H}_{6}}} \times 100 \%
\end{gathered}
$$

Specific energy requirement (SER) of acetylene is defined as:

$$
\operatorname{SER}\left(\mathrm{kWh} / \mathrm{kg} \cdot \mathrm{C}_{2} \mathrm{H}_{2}\right)=\frac{\text { Input power }(\mathrm{kW})}{\text { Mass flow rate of } \mathrm{C}_{2} \mathrm{H}_{2}(\mathrm{~kW} / \mathrm{h})}
$$

where $Q_{\mathrm{CH}_{4}}^{0}, Q_{\mathrm{C}_{2} \mathrm{H}_{6}}^{0}$ represent the volume flow of $\mathrm{CH}_{4}$ and $\mathrm{C}_{2} \mathrm{H}_{6}$ in the feedstock, respectively, and $Q_{\mathrm{C}_{2} \mathrm{H}_{2}}, Q_{\mathrm{CH}_{4}}, Q_{\mathrm{C}_{2} \mathrm{H}_{6}}$ are the volume flow of $\mathrm{C}_{2} \mathrm{H}_{2}, \mathrm{CH}_{4}$, and $\mathrm{C}_{2} \mathrm{H}_{6}$ in the product.

\section{Results and Discussion}

\subsection{Effect of Nitrogen/Oxygen Substances on Methane Pyrolysis}

It has been acknowledged that the thermal energy is the critical point for pyrolysis of hydrocarbons to acetylene by thermal plasma, but the mass and heat transfer mechanism in the reaction system is difficult to describe quantitatively. Up to now, the accredited mechanism and sequence of chemical transformations during the pyrolysis of saturated hydrocarbons is described below [14]:

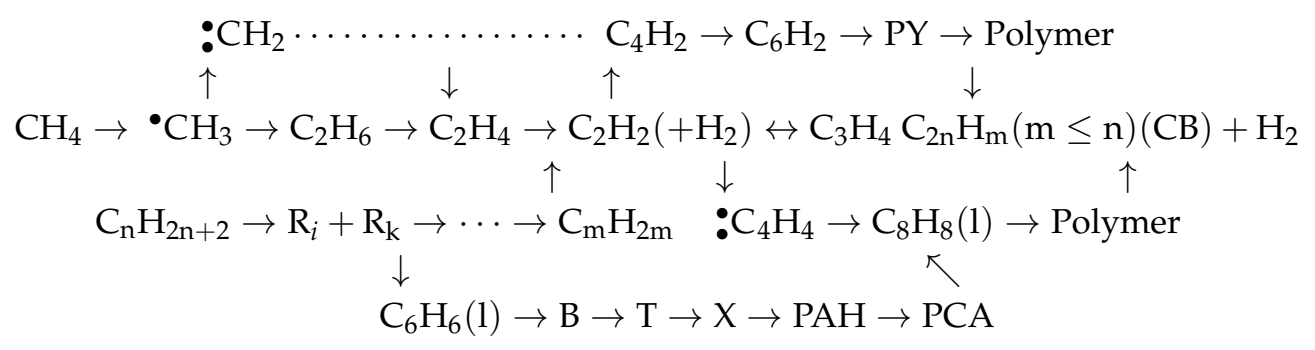

However, because $\mathrm{CO}_{2}, \mathrm{~N}_{2}$, and $\mathrm{CO}$ may also decompose in the atmosphere and react with the intermediate product of alkane pyrolysis in Equation (8), their presence in alkane-rich feed gas is expected to influence the pyrolysis products. To clarify the effect of each of them, $\mathrm{CO}_{2}, \mathrm{~N}_{2}$, and $\mathrm{CO}$ were respectively mixed into methane (as a representative alkane) to serve as a binary feed gas for pyrolysis. The experimental conditions are as follows: the molar ratio of input $\mathrm{H}_{2} / \mathrm{CH}_{4}$ was $1.5 / 1$, the total feed rate of $\mathrm{H}_{2}$ and $\mathrm{CH}_{4}$ was $7.5 \mathrm{Nm}^{3} / \mathrm{h}$, the magnetic induction intensity was $0.077 \mathrm{~T}$, and the input power was controlled at $15 \pm 0.5 \mathrm{~kW}$. 


\subsubsection{Effect of $\mathrm{CO}_{2}$ on Methane Pyrolysis}

By adding different amount of $\mathrm{CO}_{2}$ in methane, the $\mathrm{CO}_{2}$ volume fraction changed in the range of $2-14 \%$. The plasma-enhanced process of oxidation conversion may be explained as the reaction below in Equation (9) along with reactions in Equation (8):

$$
\mathrm{CH}_{4}+\mathrm{CO}_{2} \rightarrow 2 \mathrm{CO}+2 \mathrm{H}_{2} \quad \Delta \mathrm{H}=+247 \mathrm{~kJ} / \mathrm{mol}
$$

Figure 2 shows the effect of $\mathrm{CO}_{2}$ content on the kinds of products, including mainly hydrocarbons, $\mathrm{CO}_{2}$, and $\mathrm{CO}$, at an input power of $15 \mathrm{~kW}$. As can be seen from the figure, with the increase in $\mathrm{CO}_{2}$ content, the mole fraction of $\mathrm{C}_{2} \mathrm{H}_{2}$ reduced from $8.4 \%$ to $6.3 \%$ and $\mathrm{C}_{2} \mathrm{H}_{4}$ concentration reduced slightly from $0.61 \%$ to $0.31 \%$. This is mainly ascribed to a competitive relationship between the oxygen-free pyrolysis reactions in Equation (8) and oxidation reaction in Equation (9), and the oxidation reaction hindered the dominant pyrolysis reactions that produce $\mathrm{C}_{2} \mathrm{H}_{2}$. This is also supported by the result that increasing $\mathrm{CO}_{2}$ content in the feed gas improved the $\mathrm{CO}$ content in the product. On the contrary, $\mathrm{CH}_{4}$ content in the product ascended from $10.1 \%$ to $15.2 \%$ although the $\mathrm{CH}_{4}$ content in the feed gas was slightly reduced when adding $\mathrm{CO}_{2}$. This is probably because when the $\mathrm{CO}_{2}$ content increased, the pyrolysis of $\mathrm{CO}_{2}$ to $\mathrm{CO}$ and $\mathrm{O}$ - radicals consume a great deal of input energy, which restricted the conversion of $\mathrm{CH}_{4}$ by either Equation (8) or Equation (9).

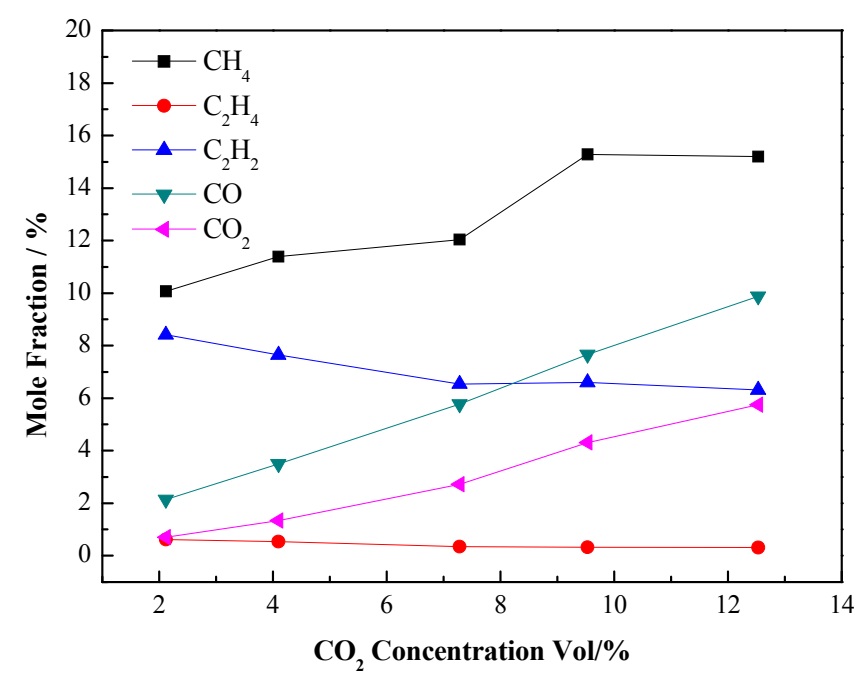

Figure 2. The effect of $\mathrm{CO}_{2}$ concentration on the molar fraction of major products at $15 \mathrm{~kW}$ (total gas flow rate of methane and hydrogen: $7.5 \mathrm{Nm}^{3} / \mathrm{h}$; magnetic flux intensity: $0.077 \mathrm{~T}$ ).

Figure 3 illustrates the effect of $\mathrm{CO}_{2}$ content on the yield $(Y)$ of $\mathrm{C}_{2} \mathrm{H}_{2}$ and $\mathrm{CH}_{4}$ conversion efficiency $(C E)$ at $15 \mathrm{~kW}$. With the increase of $\mathrm{CO}_{2}$ content, the yield of $\mathrm{C}_{2} \mathrm{H}_{2}$ and $\mathrm{CH}_{4}$ conversion efficiency showed a synchronous decreasing trend. This is consistent to the results of Figure 2, suggesting that the increase of $\mathrm{CO}_{2}$ content was not conducive to the pyrolysis reaction based on the fact that more input energy was taken away by both the pyrolysis of $\mathrm{CO}_{2}$ and the endothermic reaction Equation (9). The effect of different $\mathrm{CO}_{2}$ content on the $S E R$ of $\mathrm{C}_{2} \mathrm{H}_{2}$ was illustrated in Figure 4 . With the increase of $\mathrm{CO}_{2}$ content, the $S E R$ of $\mathrm{C}_{2} \mathrm{H}_{2}$ was rising. This directly revealed that the higher the proportion of $\mathrm{CO}_{2}$ in the reaction system, the more energy was consumed by side-reactions. From the viewpoint of product composition and energy utilization, the presence of $\mathrm{CO}_{2}$ was not conducive to the pyrolysis production of $\mathrm{C}_{2} \mathrm{H}_{2}$ and it should be removed from alkane-rich feed gas before the reaction. 


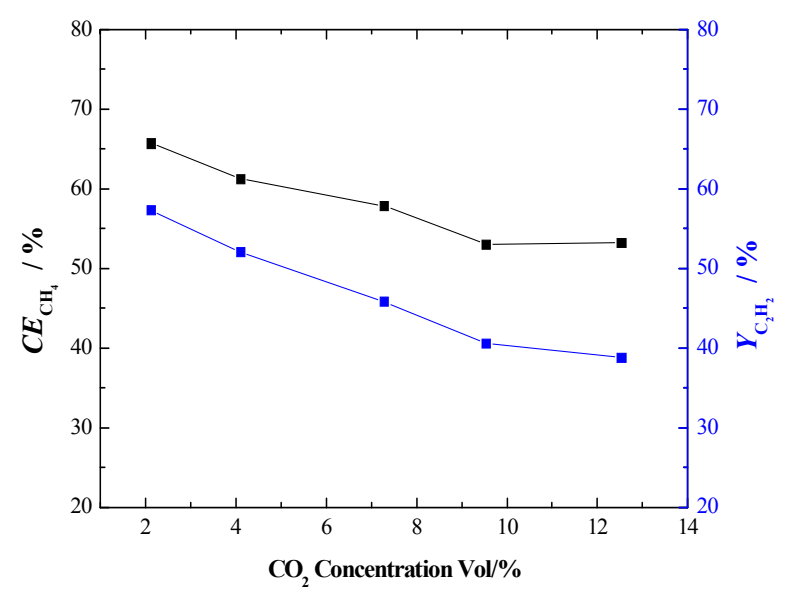

Figure 3. The effect of $\mathrm{CO}_{2}$ concentration on the yield of $\mathrm{C}_{2} \mathrm{H}_{2}$, conversion efficiency of $\mathrm{CH}_{4}$ at $15 \mathrm{~kW}$ (total gas flow rate of methane and hydrogen: $7.5 \mathrm{Nm}^{3} / \mathrm{h}$; magnetic flux intensity: $0.077 \mathrm{~T}$ ).

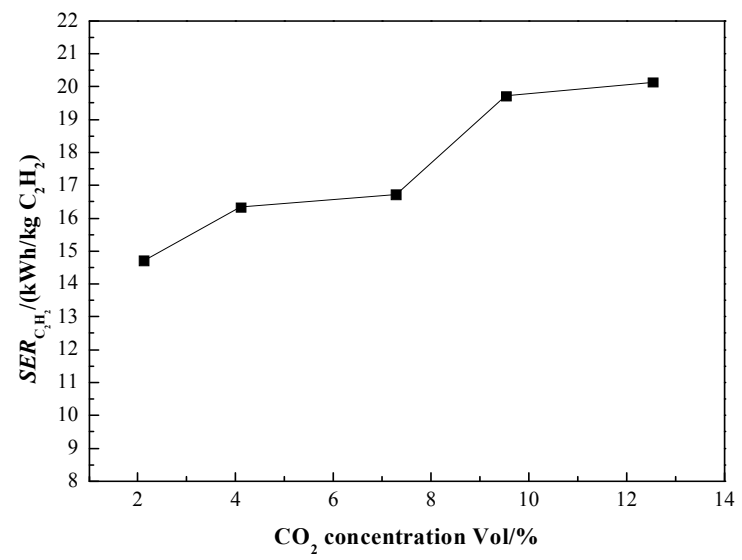

Figure 4. The effect of $\mathrm{CO}_{2}$ concentration on $S E R$ of $\mathrm{C}_{2} \mathrm{H}_{2}$ at $15 \mathrm{~kW}$ (total gas flow rate of methane and hydrogen: $7.5 \mathrm{Nm}^{3} / \mathrm{h}$; magnetic flux intensity: $0.077 \mathrm{~T}$ ).

\subsubsection{Effect of $\mathrm{CO}$ on Methane Pyrolysis}

The content of $\mathrm{CO}$ in several alkane-rich gases such as coke oven gas cannot be ignored, so it is significant to explore the effect of $\mathrm{CO}$ on the pyrolysis of alkanes. Figure 5 showed the effect of $\mathrm{CO}$ content on the concentration of major gaseous compounds, with $\mathrm{CO}$ volume fraction changing in the range of $2-14 \%$. As seen from the diagram, there was basically no change in the molar fraction of major hydrocarbon products, with $\mathrm{CH}_{4}$ maintained $13.1-14.1 \%, \mathrm{C}_{2} \mathrm{H}_{2} 10.4-11.1 \%$, and $\mathrm{C}_{2} \mathrm{H}_{4} 0.59-0.68 \%$. As for the changes of $\mathrm{CO}$ and $\mathrm{CO}_{2}$ content in the pyrolysis products, only a very small amount of $\mathrm{CO}_{2}$ was detected with a linear increase of the $\mathrm{CO}$ content in the product, and the $\mathrm{CO}$ content in the product was very close to that in the feed gas, indicating that $\mathrm{CO}$ was almost not involved in the reactions. This is ascribed to the relatively inert character of $\mathrm{CO}$ due to the very large energy of carbon-oxygen triple bond in CO molecule $(1072 \mathrm{~kJ} / \mathrm{mol})$.

Figure 6 shows the effect of $\mathrm{CO}$ content on the yield of $\mathrm{C}_{2} \mathrm{H}_{2}$ and $\mathrm{CH}_{4}$ conversion efficiency in the pyrolysis products at $15 \mathrm{~kW}$. Agreeing with the above analysis, both the yield of $\mathrm{C}_{2} \mathrm{H}_{2}$ and $\mathrm{CH}_{4}$ conversion efficiency changed only slightly with the $\mathrm{CO}$ content in the feed gas. This is also the case for the influence of $\mathrm{CO}$ content on the $S E R$ of $\mathrm{C}_{2} \mathrm{H}_{2}$ (Figure 7). This revealed that within the scope of the experiment, the $\mathrm{CO}$ content in the reactant had little influence on the pyrolysis of alkanes. Therefore, the separation of $\mathrm{CO}$ from alkane-rich gas is not always necessary before the pyrolysis process, and it can be conducted after pyrolysis because the separation of $\mathrm{CO}$ from $\mathrm{C}_{2} \mathrm{H}_{2}$ will be easier than from alkanes. The $\mathrm{C}_{2} \mathrm{H}_{2}$ molecule is a notable hydrogen-bond donor due to the weak hydrogen-bonding 
acidity of its C-H bond, thus, it can be readily dissolved/adsorbed from non-acidic $\mathrm{CO}$ and alkanes by dipolar aprotic solvent, ionic liquids, or anion-pillared microporous frameworks [15,16].

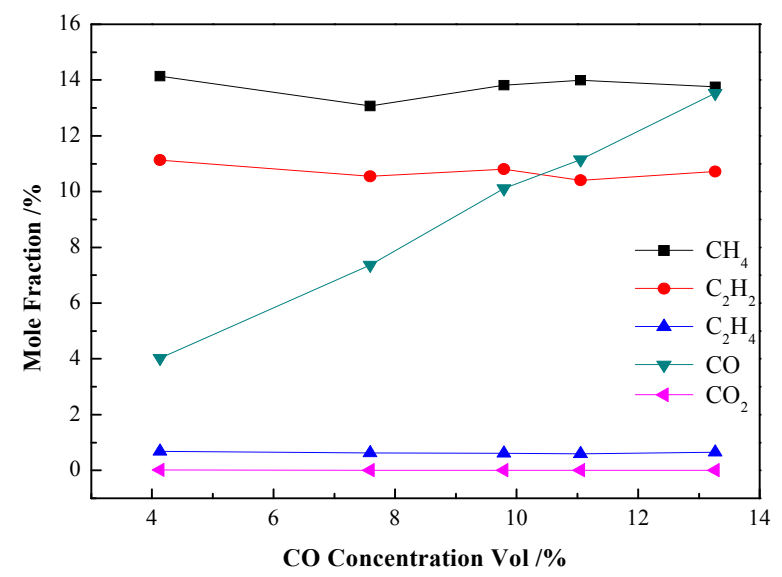

Figure 5. The effect of $\mathrm{CO}$ concentration on the molar fraction of major products at $15 \mathrm{~kW}$ (total gas flow rate of methane and hydrogen: $7.5 \mathrm{Nm}^{3} / \mathrm{h}$; magnetic flux intensity: $0.077 \mathrm{~T}$ ).

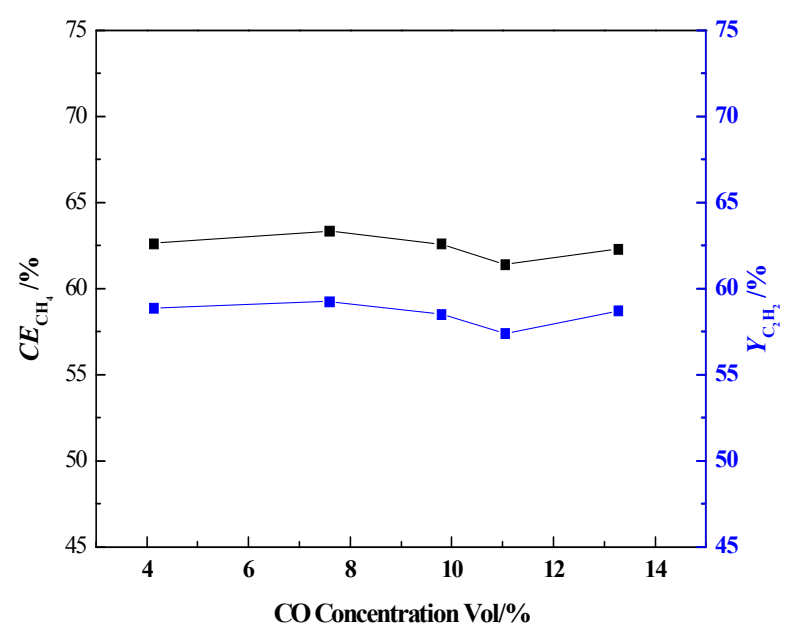

Figure 6. The effect of $\mathrm{CO}$ concentration on the yield of $\mathrm{C}_{2} \mathrm{H}_{2}$, conversion efficiency of $\mathrm{CH}_{4}$ at $15 \mathrm{~kW}$ (total gas flow rate of methane and hydrogen: $7.5 \mathrm{Nm}^{3} / \mathrm{h}$; magnetic flux intensity: $0.077 \mathrm{~T}$ ).

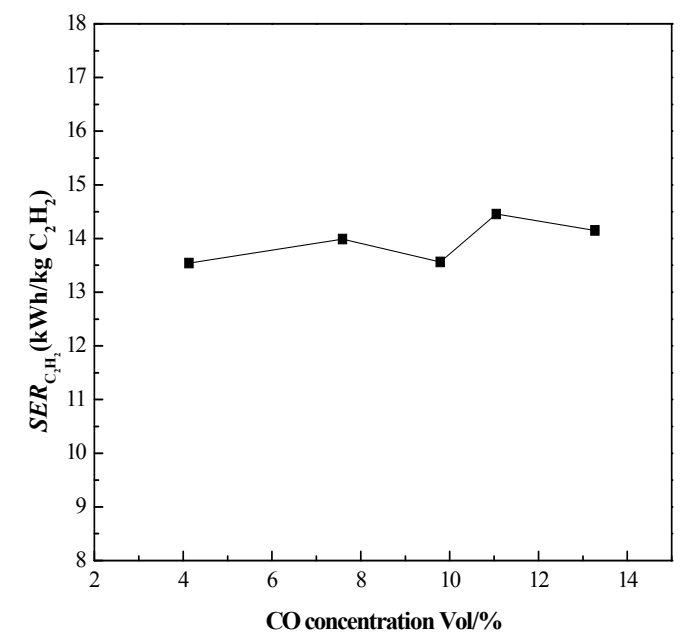

Figure 7. The effect of $\mathrm{CO}$ concentration on SER of $\mathrm{C}_{2} \mathrm{H}_{2}$ at $15 \mathrm{~kW}$ (total gas flow rate of methane and hydrogen: $7.5 \mathrm{Nm}^{3} / \mathrm{h}$; magnetic flux intensity: $0.077 \mathrm{~T}$ ). 


\subsubsection{Effect of $\mathrm{N}_{2}$ on Methane Pyrolysis}

By adding different volume fractions of $\mathrm{N}_{2}(2-14 \%)$ to the alkane-rich gas, its effect was investigated in this part, as shown in Figure 8. Along with the $\mathrm{N}_{2}$ concentration increasing, the changes of hydrocarbons content in the product are obvious. The molar fraction of $\mathrm{CH}_{4}$ increased from $9.4 \%$ to $14.1 \%$, while the $\mathrm{C}_{2} \mathrm{H}_{2}$ decreased from $12 \%$ to $8.7 \%$, and the $\mathrm{C}_{2} \mathrm{H}_{4}$ concentration dropped from $0.82 \%$ to $0.49 \%$. As for the $\mathrm{N}_{2}$ and $\mathrm{HCN}$, the content of $\mathrm{N}_{2}$ in the product ascended significantly while the $\mathrm{HCN}$ content increased slightly. The $\mathrm{N}_{2}$ fraction in the product was notably lower than that in the feed gas, indicating that a part of $\mathrm{N}_{2}$ was decomposed in the plasma environment and generated HCN, as shown in Equation (10), although the energy to break up the $\mathrm{N} \equiv \mathrm{N}$ bond in nitrogen was relatively large $(946 \mathrm{KJ} / \mathrm{mol})$. The process of breaking $\mathrm{N} \equiv \mathrm{N}$ bonds consumed the input energy that was originally intended to pyrolyze $\mathrm{CH}_{4}$, thus, both the conversion efficiency of $\mathrm{CH}_{4}$ and the yield of $\mathrm{C}_{2} \mathrm{H}_{2}$ decreased (Figure 9), and the $\mathrm{CH}_{4}$ fraction in the product gas increased, while $\mathrm{C}_{2} \mathrm{H}_{2}$ and $\mathrm{C}_{2} \mathrm{H}_{4}$ decreased (Figure 8). Consistently, the SER of $\mathrm{C}_{2} \mathrm{H}_{2}$ ascended with the increase of the $\mathrm{N}_{2}$ concentration in feed gas (Figure 10). Therefore, similar to the case of $\mathrm{CO}_{2}$, it is advisable to remove $\mathrm{N}_{2}$ from alkane-rich gas before pyrolysis, because the presence of $\mathrm{N}_{2}$ not only jeopardizes the production of $\mathrm{C}_{2} \mathrm{H}_{2}$, but also generates highly-toxic $\mathrm{HCN}$.

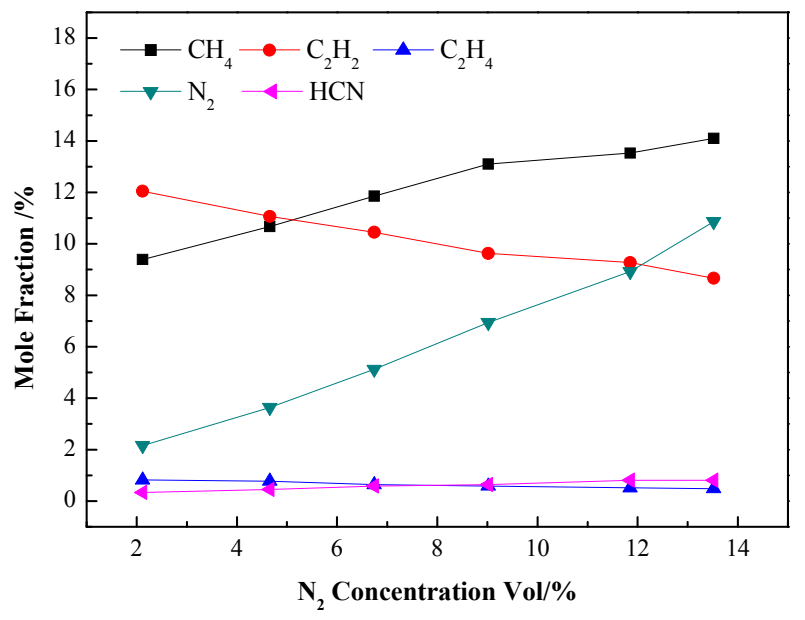

Figure 8. The effects of $\mathrm{N}_{2}$ concentration on the molar fraction of major products at $15 \mathrm{~kW}$ (total gas flow rate of methane and hydrogen: $7.5 \mathrm{Nm}^{3} / \mathrm{h}$; magnetic flux intensity: $0.077 \mathrm{~T}$ ).

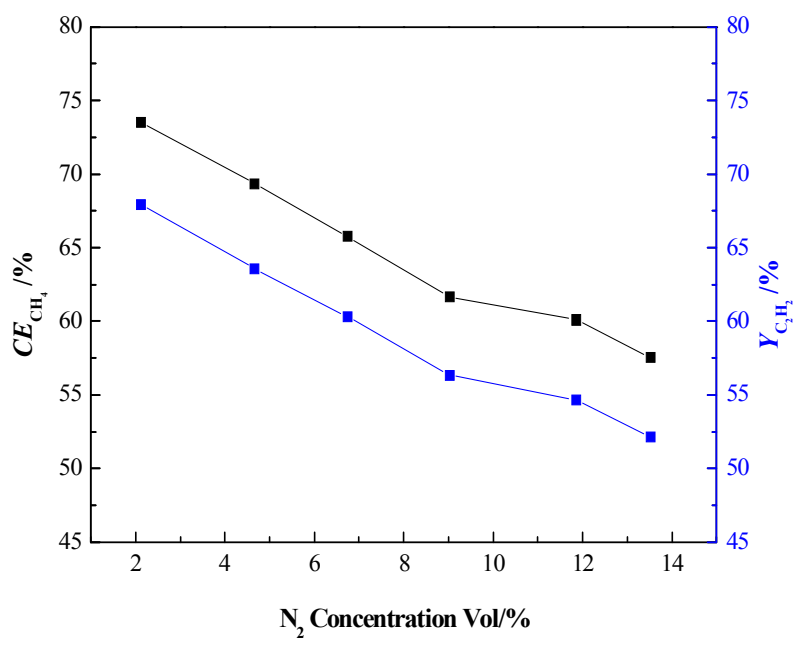

Figure 9. The effects of $\mathrm{N}_{2}$ content on yield of $\mathrm{C}_{2} \mathrm{H}_{2}$ and conversion efficiency of $\mathrm{CH}_{4}$ at $15 \mathrm{~kW}$ (total gas flow rate of methane and hydrogen: $7.5 \mathrm{Nm}^{3} / \mathrm{h}$; magnetic flux intensity: $0.077 \mathrm{~T}$ ). 


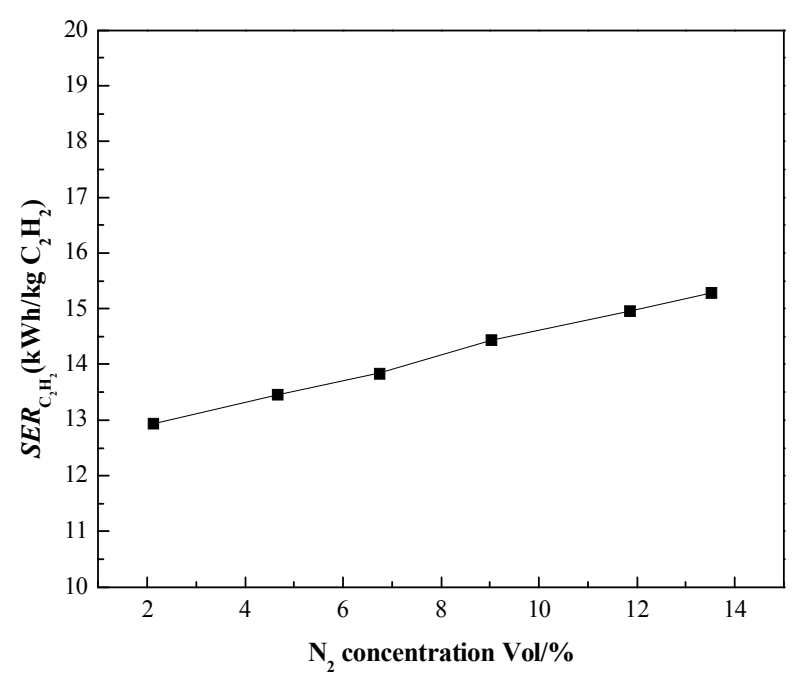

Figure 10. The effects of $\mathrm{N}_{2}$ content on $S E R$ of $\mathrm{C}_{2} \mathrm{H}_{2}$ at $15 \mathrm{~kW}$ (total gas flow rate of methane and hydrogen: $7.5 \mathrm{Nm}^{3} / \mathrm{h}$; magnetic flux intensity: $0.077 \mathrm{~T}$ ).

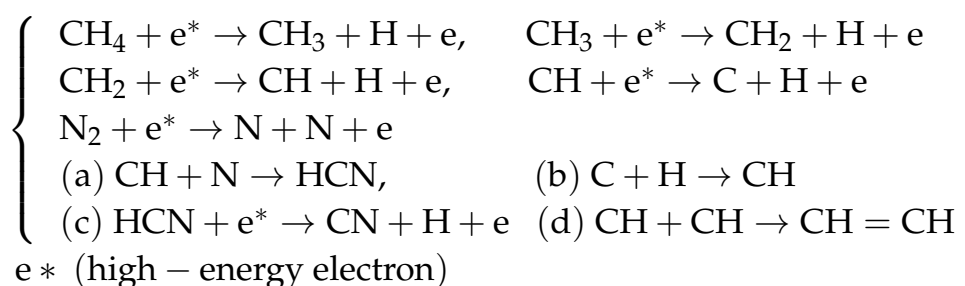

\subsection{Pyrolysis of Simulated Coke Oven Gas}

Coke oven gas is a typical alkane-rich mixed gas containing many nitrogen/oxygen compounds, thus, the simulated coke oven gas shown in Table 1 was used for further investigation on the pyrolysis process of alkane-rich gas by a rotating arc thermal plasma reactor. The influences of input power and feed rate on the pyrolysis process were investigated as they are two important operation parameters in pyrolysis.

\subsubsection{Influence of Input Power on the Simulated COG Pyrolysis Process}

The investigated experimental conditions were listed as follows: feed rate of $7.5 \mathrm{Nm}^{3} / \mathrm{h}$, magnetic induction intensity of $0.077 \mathrm{~T}$, and input power of $13-26 \mathrm{~kW}$. Figure 11 presents the influence of the input power on the molar fraction of main products. It can be seen that the content of $\mathrm{CH}_{4}, \mathrm{CO}_{2}$, and $\mathrm{N}_{2}$ decreased gradually, while CO increased from $6.2 \%$ to $7.1 \%$ and $\mathrm{HCN}$ increased from $0.43 \%$ to $0.76 \%$ in the whole power range. This is because the increase of input power promoted the transformation of alkanes through not only the desired reactions (toward $\mathrm{C}_{2} \mathrm{H}_{2}$ ), but also side reactions. This is also reflected in Figure 12, where the conversion efficiency of alkanes increased with the rise in power. The presence of $\mathrm{CO}$ and $\mathrm{HCN}$ in the product gas was a result of the pyrolysis of $\mathrm{CO}_{2}$ and $\mathrm{N}_{2}$ in the feed gas, as demonstrated by the previous sections. As for the hydrocarbon products, $\mathrm{C}_{2} \mathrm{H}_{6}$ content did not change obviously, only a small amount, because of its small content in the feed and similar pyrolysis properties to methane. $\mathrm{C}_{2} \mathrm{H}_{4}$ maintained a low content at first, and then increased from $0.64 \%$ to $3.3 \%$. However, the change of $\mathrm{C}_{2} \mathrm{H}_{2}$ content was complex, showing an increasing trend at first, and then decreasing from $8.0 \%$ to $4.4 \%$. Correspondingly, as Figure 13 displays, when the power increased from $12.9 \mathrm{~kW}$ to $21.6 \mathrm{~kW}$, the $\mathrm{C}_{2} \mathrm{H}_{2}$ yield rose from $54.8 \%$ to $68.3 \%$, and then it dropped to $42.7 \%$ with a continual increase of power. As for the $\mathrm{C}_{2} \mathrm{H}_{2}$ selectivity, it maintained above $90.3 \%$ when the power was between $12.9 \mathrm{~kW}$ to $17.9 \mathrm{~kW}$, and then it dropped to $51.0 \%$. The $S E R$ of $\mathrm{C}_{2} \mathrm{H}_{2}$ also exhibited similar change (Figure 12). When the power ascended from $12.9 \mathrm{~kW}$ to $21.6 \mathrm{~kW}$, the $S E R$ of $\mathrm{C}_{2} \mathrm{H}_{2}$ increased 
slowly from $16.7 \mathrm{kWh} / \mathrm{kg} \mathrm{C}_{2} \mathrm{H}_{2}$ to $18.8 \mathrm{kWh} / \mathrm{kg} \mathrm{C}_{2} \mathrm{H}_{2}$, but then increased rapidly from $18.8 \mathrm{kWh} / \mathrm{kg}$ $\mathrm{C}_{2} \mathrm{H}_{2}$ to $41 \mathrm{kWh} / \mathrm{kg} \mathrm{C}_{2} \mathrm{H}_{2}$ when the power continued to increase from $21.6 \mathrm{~kW}$ to $25.6 \mathrm{~kW}$.

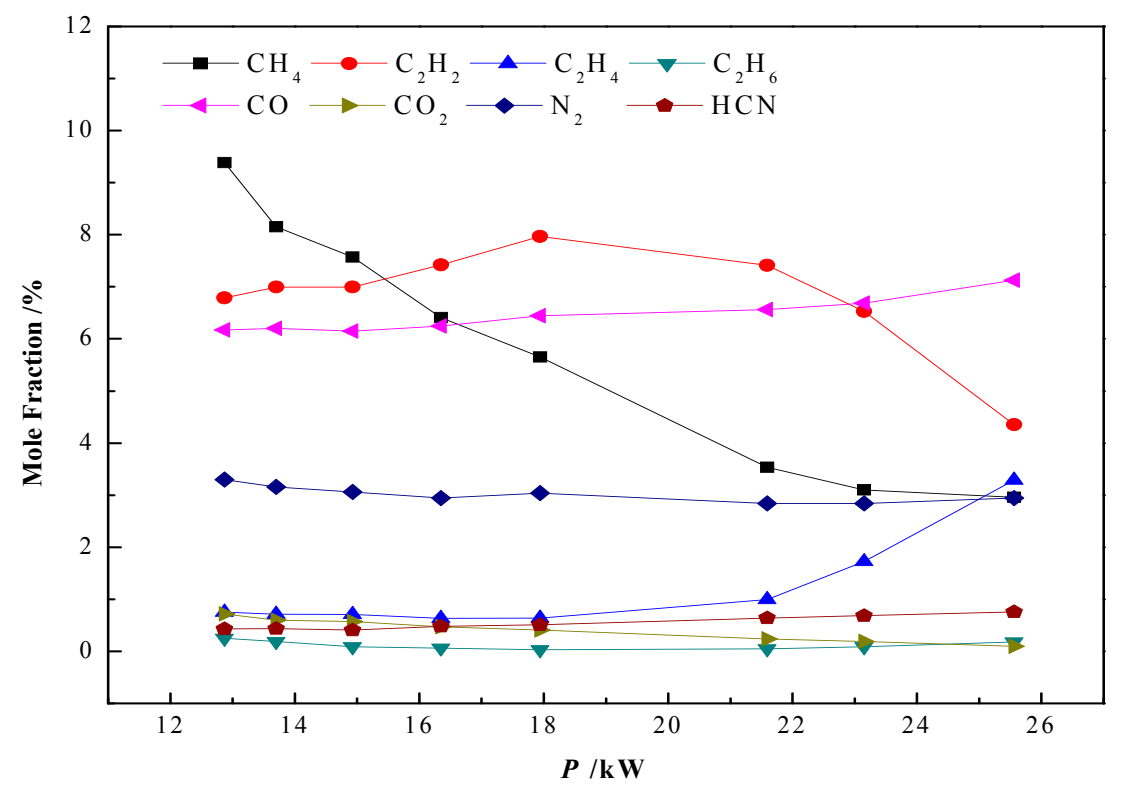

Figure 11. The effect of input power on the molar fraction of major products in the pyrolysis of simulated coke oven gas (total gas flow rate of simulated coke oven gas: $7.5 \mathrm{Nm}^{3} / \mathrm{h}$; magnetic flux intensity: $0.077 \mathrm{~T}$ ).

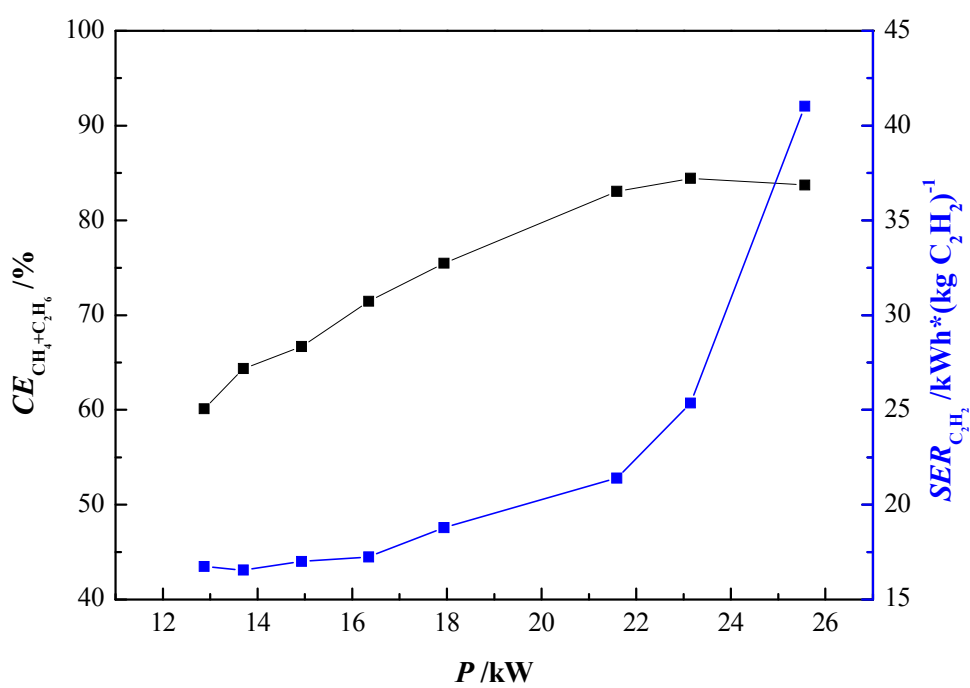

Figure 12. The effects of input power on the conversion of alkanes and $S E R$ of $\mathrm{C}_{2} \mathrm{H}_{2}$ in the pyrolysis of simulated coke oven gas (total gas flow rate of simulated coke oven gas: $7.5 \mathrm{Nm}^{3} / \mathrm{h}$; magnetic flux intensity: 0.077 T).

This could be attributed to the dual effect of the input power on the pyrolysis. On one hand, increasing input power can provide more energy to convert the components in feed gas and, thus, produce more $\mathrm{C}_{2} \mathrm{H}_{2}$. On the other hand, increasing input power will also elevate the temperature in the reactor, and once the temperature is too high, the generated metastable $\mathrm{C}_{2} \mathrm{H}_{2}$ decomposes into solid carbon and $\mathrm{H}_{2}$. Therefore, there should be an optimum input power for the pyrolysis of alkane-rich gases to produce the $\mathrm{C}_{2} \mathrm{H}_{2}$-rich product gas. In the current experiment, taking the various factors into consideration, an input power of approximately $17.9 \mathrm{~kW}$ was a desired condition for pyrolysis because 
it combined high alkane conversion (75.4\%), high $\mathrm{C}_{2} \mathrm{H}_{2}$ yield (68.3\%) and selectivity $(91.2 \%)$, and low SER $\left(18.8 \mathrm{kWh} / \mathrm{kgC}_{2} \mathrm{H}_{2}\right)$.

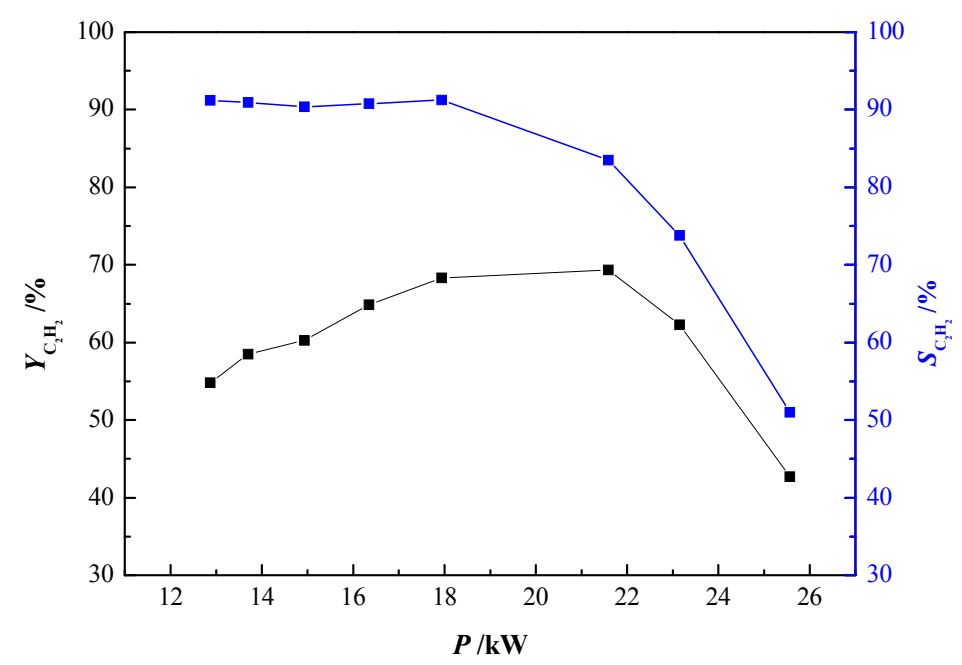

Figure 13. The effects of input power on the yield and selectivity of $\mathrm{C}_{2} \mathrm{H}_{2}$ in the pyrolysis of simulated coke oven gas (total gas flow rate of simulated coke oven gas: $7.5 \mathrm{Nm}^{3} / \mathrm{h}$; magnetic flux intensity: $0.077 \mathrm{~T})$.

\subsubsection{Influence of Feed Rate on the Simulated COG Pyrolysis Process}

Experimental conditions in investigating the influence of feed rate are listed as follows: input power of $15 \pm 0.5 \mathrm{~kW}$, magnetic induction intensity of $0.077 \mathrm{~T}$, and feed rate of $3.6-10 \mathrm{Nm}^{3} / \mathrm{h}$. Figure 14 exhibits the effect of the feed rate on the major products' content. With the increase of the feed rate, the $\mathrm{CO}$ fraction showed a decreasing trend in the pyrolysis product from $7.5 \%$ to $6.2 \%$, and the $\mathrm{CO}_{2}$ fraction had a sensible growth from $0.042 \%$ to $0.79 \%$, implying that the reaction in Equation (9) was weakened to some extent. At the same time, the side reaction of $\mathrm{N}_{2}$ in Equation (10) also became slightly weakened, as indicated by the results that with the increase of the feeding rate, the $\mathrm{N}_{2}$ content in the product increased slightly overall, while the content of HCN slightly decreased. The content of $\mathrm{C}_{2} \mathrm{H}_{4}$ and $\mathrm{C}_{2} \mathrm{H}_{6}$ hardly changed, as could be seen as the molar fraction of $\mathrm{C}_{2} \mathrm{H}_{4}$ was between $0.63 \%$ and $0.85 \%$, and that of $\mathrm{C}_{2} \mathrm{H}_{6}$ was below $0.26 \%$. The most obvious and important changes were the levels of $\mathrm{CH}_{4}$ and $\mathrm{C}_{2} \mathrm{H}_{2}$. With the increase of the feed rate, the molar fraction of $\mathrm{CH}_{4}$ in the product increased sharply from $0.86 \%$ to $10.4 \%$, but that of $\mathrm{C}_{2} \mathrm{H}_{2}$ dropped from $9.5 \%$ to $6.2 \%$. This suggested that more $\mathrm{CH}_{4}$ was not cracked as the feeding rate increased, resulting in an increase in the $\mathrm{CH}_{4}$ mole fraction and a dilution of $\mathrm{C}_{2} \mathrm{H}_{2}$. In fact, as shown in Figures 15 and 16, the alkanes' conversion efficiency decreased rapidly from $96.1 \%$ to $56 \%$, but the $\mathrm{C}_{2} \mathrm{H}_{2}$ selectivity remained at a high level, between $88.1 \%$ and $90 \%$. This indicated that when the alkane conversion efficiency decreased, the side reactions were not enhanced, and the conversion of alkanes was still dominated by the formation of $\mathrm{C}_{2} \mathrm{H}_{2}$. As the conversion of alkanes decreased, and $\mathrm{C}_{2} \mathrm{H}_{2}$ selectivity remained unchanged, the yield of $\mathrm{C}_{2} \mathrm{H}_{2}$ decreased with the increase of the feed rate, from $84.7 \%$ to $50.3 \%$. Moreover, the SER of $\mathrm{C}_{2} \mathrm{H}_{2}$ was reduced from $26.4 \mathrm{kWh} / \mathrm{kg} \mathrm{C}_{2} \mathrm{H}_{2}$ to $15.8 \mathrm{kWh} / \mathrm{kg} \mathrm{C} \mathrm{C}_{2} \mathrm{H}_{2}$. The phenomenon above was probably the result of the shorter gas residence time and lower temperature in the reactor caused by the increase of the feed rate, which made it difficult to convert the increased alkanes into $\mathrm{C}_{2} \mathrm{H}_{2}$ in time.

In the entire range of the flow rates investigated, the $\mathrm{C}_{2} \mathrm{H}_{2}$ selectivity was always maintained at a high level, but the conversion of alkanes and the yield of $\mathrm{C}_{2} \mathrm{H}_{2}$ decreased with the flow rate. This indicated that the processing capacity of alkanes was limited under this input power, and the feed rate could be appropriately increased to obtain optimum technical and economic performance. 


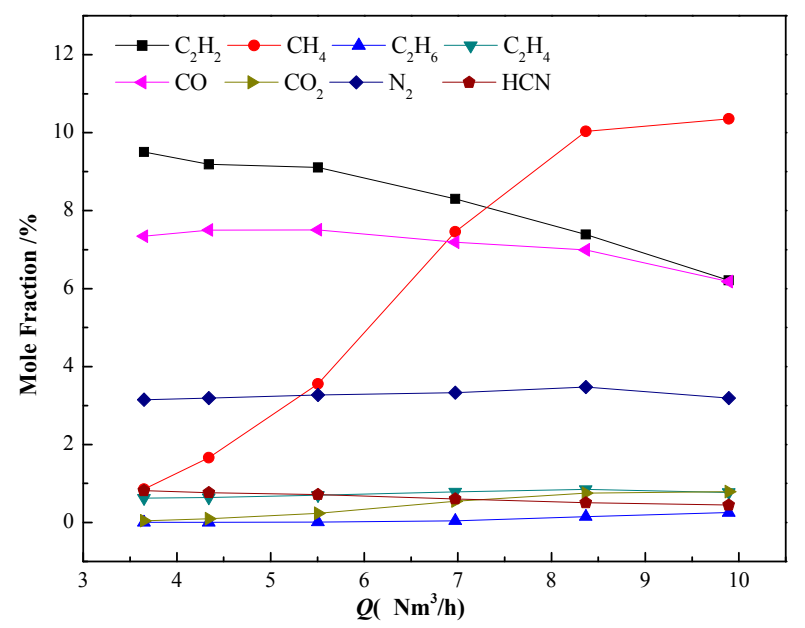

Figure 14. The effects of feeding flow rate on the molar fraction of major products in the pyrolysis of siimulated coke oven gas (input power: $15 \pm 0.5 \mathrm{~kW}$; magnetic flux intensity: 0.077 T).

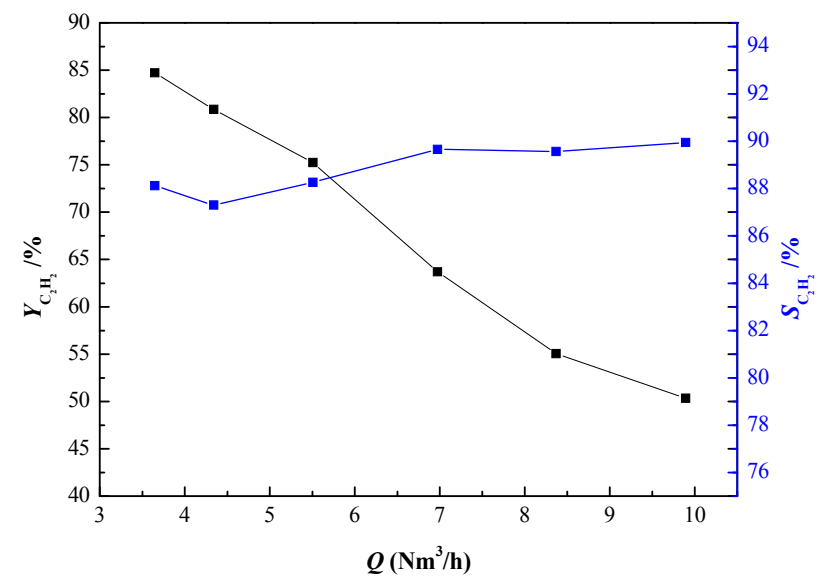

Figure 15. The effects of feed rate on the yield and selectivity of $\mathrm{C}_{2} \mathrm{H}_{2}$ in the pyrolysis of simulated coke oven gas (input power: $15 \pm 0.5 \mathrm{~kW}$; magnetic flux intensity: $0.077 \mathrm{~T}$ ).

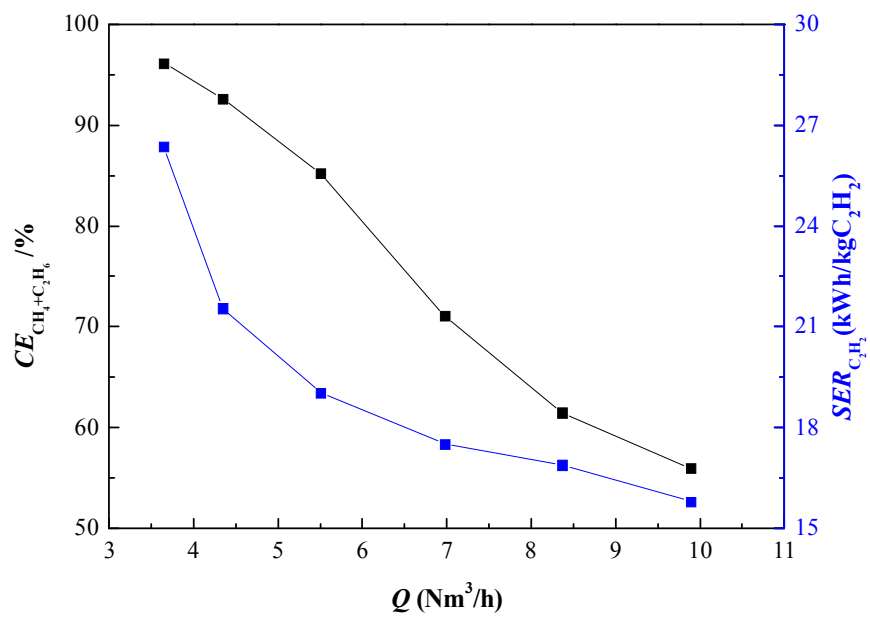

Figure 16. The effects of the feed rate on the conversion efficiency of alkanes and $S E R$ of $\mathrm{C}_{2} \mathrm{H}_{2}$ in pyrolysis of simulated coke oven gas (input power: $15 \pm 0.5 \mathrm{~kW}$; magnetic flux intensity: $0.077 \mathrm{~T}$ ).

In this work, the effect of various nitrogen/oxygen-containing substances including $\mathrm{N}_{2}, \mathrm{CO}$, and $\mathrm{CO}_{2}$ on the pyrolysis of $\mathrm{CH}_{4}$ to $\mathrm{C}_{2} \mathrm{H}_{2}$ was conducted by thermal plasma, as well as pyrolysis of 
simulated coke oven gas as a model of alkane-rich gas. The above experimental results indicated that nitrogen/oxygen-containing substances $\mathrm{CO}_{2}$ and $\mathrm{N}_{2}$ had palpable and negative effects on the pyrolysis process, whereas $\mathrm{CO}$ exhibited little effect. Therefore, the following technical flow is advisable for the pyrolysis process: separate $\mathrm{CO}_{2}$ and $\mathrm{N}_{2}$ from the alkane-rich feed gas at first, and then pyrolyze the feed gas with a rotary thermal plasma reactor to produce $\mathrm{C}_{2} \mathrm{H}_{2}$-rich pyrolysis gas, and, finally, separate $\mathrm{C}_{2} \mathrm{H}_{2}$ from the other components, including $\mathrm{CO}$, in the pyrolysis gas.

\section{Conclusions}

The influence of nitrogen/oxygen substances $\mathrm{CO}_{2}, \mathrm{~N}_{2}$, and $\mathrm{CO}$ for the pyrolysis of alkane-rich mixing gases to produce $\mathrm{C}_{2} \mathrm{H}_{2}$ had been illustrated for the first time, using a $50 \mathrm{~kW}$ self-made rotary thermal plasma reactor. In the mole fraction range of $2-14 \%, \mathrm{~N}_{2}$ and $\mathrm{CO}$ had negative effects on the main reaction that converted $\mathrm{CH}_{4}$ to $\mathrm{C}_{2} \mathrm{H}_{2}$, while $\mathrm{CO}$ had little effect. Considering this difference, along with the toxicity of byproducts and the level of difficulty in separating different gas mixtures, it is advisable to remove $\mathrm{CO}_{2}$ and $\mathrm{N}_{2}$ from the feed gas before pyrolysis, and to separate the product gas from $\mathrm{CO}$ after pyrolysis. The pyrolysis of simulated coke oven gas, an important alkane-rich mixing gas containing $\mathrm{CO}_{2}, \mathrm{~N}_{2}$, and $\mathrm{CO}$, was also conducted in this work, and the effect of the input power and feeding rate on pyrolysis were investigated. Considering the non-monotonic change of $\mathrm{C}_{2} \mathrm{H}_{2}$ selectivity and yield, along with the input power, the selectivity of $\mathrm{C}_{2} \mathrm{H}_{2}$ up to $91.2 \%$ and a $\mathrm{C}_{2} \mathrm{H}_{2}$ yield of $68.3 \%$ were obtained at the input power of $17.9 \mathrm{~kW}$. Higher $\mathrm{C}_{2} \mathrm{H}_{2}$ selectivity and a lower $\mathrm{C}_{2} \mathrm{H}_{2}$-specific energy requirement could be obtained when the feed rate was increased, although at the expense of lower alkane conversion and $\mathrm{C}_{2} \mathrm{H}_{2}$ yield. Overall, the experimental results revealed that it was a promising method to convert alkane-rich gases to value-added chemicals, and provided indispensable information for creating a technical flow for a whole process integrating pretreatment, pyrolysis, and posttreatment.

Acknowledgments: This work was supported by the National Key Research and Development Program of China (2016YFB0301800).

Author Contributions: Baogen Su and Qiwei Yang conceived and designed the experiments. Junkui Jin and Wei Huang performed the experiments, and all the authors analyzed the data. Wei Huang wrote the paper.

Conflicts of Interest: The authors declare no conflict of interest. The founding sponsors had no role in the design of the study; in the collection, analyses, or interpretation of data; in the writing of the manuscript; or in the decision to publish the results.

\section{References}

1. Agency, I.E. Tracking Industrial Energy Efficiency and $\mathrm{CO}_{2}$ Emissions; Organizations for Economic Co-Operation and Development: Paris, France, 2007.

2. Munoz-Escalona, P.; Payares, M.C.; Dorta, M.; Diaz, R. Analysis and influence of acetylene and propane gas during oxyfuel gas cutting of 1045 carbon steel. J. Mater. Eng. Perform. 2006, 15, 684-692. [CrossRef]

3. Schobert, H. Production of acetylene and acetylene-based chemicals from coal. Chem. Rev. 2014, 114, 1743-1760. [CrossRef] [PubMed]

4. Diercks, R.; Arndt, J.D.; Freyer, S.; Geier, R.; Machhammer, O.; Schwartze, J.; Volland, M. Raw material changes in the chemical industry. Chem. Eng. Technol. 2008, 31, 631-637. [CrossRef]

5. Slovetskii, D.I. Plasma-chemical processes in petroleum chemistry (review). Pet. Chem. 2006, 46, $295-304$. [CrossRef]

6. Zhang, M.; Ma, J.; Su, B.G.; Wen, G.D.; Yang, Q.W.; Ren, Q.L. Pyrolysis of polyolefins using rotating arc plasma technology for production of acetylene. Energies 2017, 10, 513. [CrossRef]

7. Bond, R.L.; Ladner, W.R.; Mcconnell, G.I.T.; Galbraith, I.F. Production of acetylene from coal, using a plasma jet. Nature 1963, 200, 1313-1314. [CrossRef]

8. Beiers, H.G.; Baumann, H.; Bittner, D.; Klein, J.; Juntgen, H. Pyrolysis of some gaseous and liquid hydrocarbons in hydrogen plasma. Fuel 1988, 67, 1012-1016. [CrossRef] 
9. Ma, J.; Zhang, M.; Wu, J.; Yang, Q.; Wen, G.; Su, B.; Ren, Q. Hydropyrolysis of n-Hexane and Toluene to Acetylene in Rotating-Arc Plasma. Energies 2017, 10, 899. [CrossRef]

10. Ma, J.; Su, B.; Wen, G.; Yang, Q.; Ren, Q.; Yang, Y.; Xing, H. Pyrolysis of pulverized coal to acetylene in magnetically rotating hydrogen plasma reactor. Fuel Process. Technol. 2017, 167, 721-729. [CrossRef]

11. Maleki, M.; Parvin, P.; Reyhani, A.; Mortazavi, S.Z.; Moosakhani, A.; Ghorbani, Z.; Kiani, S. Decomposition of ethane molecules at atmospheric pressure using metal assisted laser induced plasma. J. Opt. Soc. Am. B Opt. Phys. 2015, 32, 493-505. [CrossRef]

12. Laktiushin, A.N.; Laktiushina, T.V. Computer synthesis by specified characteristic of the process of acetylene and technical hydrogen production from nature gas in hydrogen plasma. High Temp. Mater. Process. 2012, 16, 153-177. [CrossRef]

13. Qi, J.L.; Kong, F.R. Status and prospect for chemical utilization of coke oven gas in China. Nat. Gas Chem. Ind. 2013, 1, 013. [CrossRef]

14. Slovetsky, D.I. Modern Problems of Combustion and Its Application. In Proceedings of the IV International School-Seminar, Minsk, Belarus, 2-7 September 2001; p. 97.

15. Jin, W.B.; Li, X.N.; Zhang, Y.; Yang, Q.W.; Xing, H.B.; Ren, Q.L. Separation of structurally-related compounds with ionic liquids. Sci. China Chem. 2016, 46, 1251-1263. [CrossRef]

16. Cui, X.; Chen, K.; Xing, H.; Yang, Q.; Krishna, R.; Bao, Z.; Wu, H.; Zhou, W.; Dong, X.; Han, Y.; et al. Pore chemistry and size control in hybrid porous materials for acetylene capture from ethylene. Science 2016, 353, 141-144. [CrossRef] [PubMed]

(C) 2018 by the authors. Licensee MDPI, Basel, Switzerland. This article is an open access article distributed under the terms and conditions of the Creative Commons Attribution (CC BY) license (http:/ / creativecommons.org/licenses/by/4.0/). 